\title{
Role and Experience of a Subintensive Care Unit in Caring for Patients With COVID-19 in Italy: The CO-RESP Study
}

Sara Abram, MD, Francesco Tosello, MD, PhD, Giulia Paglietta, MD, Jacopo Davide Giamello, MD, Emanuele Bernardi, MD, Attilio Allione, MD, Giulia Cavalot, MD, Luca Dutto, MD, Fabrizio Corsini, MD, Gianpiero Martini, MD, Andrea Sciolla, MD, Sara Bernardi, MD, and Giuseppe Lauria, MD

Objective: This retrospective and prospective cohort study was designed to describe the characteristics, treatments, and outcomes of patients with SARS-CoV-2 infection (COVID-19) admitted to subintensive care units (SICU) and to identify the variables associated with outcomes. SICUs have been extremely stressed during the pandemic, but most data regarding critically ill COVID-19 patients come from intensive care units (ICUs). Studies about COVID-19 patients in SICUs are lacking.

Setting and participants: The study included 88 COVID-19 patients admitted to our SICU in Cuneo, Italy, between March and May 2020.

Measurements: Clinical and ventilatory data were collected, and patients were divided by outcome. Multivariable logistic regression analysis examined the variables associated with negative outcomes (transfer to the ICU, palliation, or death in a SICU).

Results: A total of 60 patients (68\%) had a positive outcome, and 28 patients (32\%) had a negative outcome; 69 pa- tients $(78 \%)$ underwent continuous positive airway pressure (CPAP). Pronation ( $n=37$ [42\%]) had been more frequently adopted in patients who had a positive outcome vs a negative outcome ( $\mathrm{n}=30[50 \%]$ vs $\mathrm{n}=7[25 \%] ; P=.048)$, and the median (interquartile range) $\mathrm{PaO}_{2} / \mathrm{FIO}_{2}$ ratio after 6 hours of prone positioning was lower in patients who had a negative outcome vs a positive outcome (144 [140-168] vs 249 [195268], $P=.006$ ). Independent predictors of a negative outcome were diabetes (odds ratio [OR], $8.22 ; 95 \% \mathrm{Cl}, 1.50-44.70$; $P=.015)$, higher $\mathrm{D}$-dimer (0R, $1.28 ; 95 \% \mathrm{Cl}, 1.04-1.57$; $P=.019)$, higher lactate dehydrogenase level (0R, 1.003; $95 \% \mathrm{Cl}, 1.000-1.006 ; P=.039$ ), and lower lymphocytes count (OR, 0.996; 95\% Cl, 0.993-0.999; $P=.004)$.

Conclusion: SICUs have a fundamental role in the treatment of critically ill patients with COVID-19, who require longterm CPAP and pronation cycles. Diabetes, lymphopenia, and high D-dimer and LDH levels are associated with negative outcomes.

Keywords: emergency medicine, noninvasive ventilation, prone position, continuous positive airway pressure.

\section{T} he COVID-19 pandemic has led to large increases in hospital admissions. Subintensive care units (SICUs) are among the wards most under pressure worldwide, ${ }^{1}$ dealing with the increased number of critically ill patients who need noninvasive ventilation, as well as serving as the best alternative to overfilled intensive care units (ICUs). In Italy, SICUs are playing a fundamental role in the management of COVID-19 patients, providing early treatment of respiratory failure by continuous noninvasive ventilation in order to reduce the need for intubation. ${ }^{2-5}$ Nevertheless, the great majority of available data about critically ill COVID-19 patients comes from ICUs. Full stud- ies about outcomes of patients in SICUs are lacking and need to be conducted.

We sought to evaluate the characteristics and outcomes of patients admitted to our SICU for COVID-19 to describe the treatments they needed and their impact on prognosis, and to identify the variables associated with patient outcomes.

From the Department of Emergency Medicine, Santa Croce e Carle Hospital, Cuneo, Italy (Drs. Abram, Tosello, Emanuele Bernardi, Allione, Cavalot, Dutto, Corsini, Martini, Sciolla, Sara Bernardi, and Lauria). From the School of Emergency Medicine, University of Turin, Turin, Italy (Drs. Paglietta and Giamello). 


\section{Methods}

\section{Study Design}

This cohort study used data from patients who were admitted in the very first weeks of the pandemic. Data were collected retrospectively as well as prospectively, since the ethical committee approved our project. The quality and quantity of data in the 2 groups were comparable.

Data were collected from electronic and written medical records gathered during the patient's entire stay in our SICU. Data were entered in a database with limited and controlled access. This study complied with the Declaration of Helsinki and was approved by the local ethics committees (ID: MEDURG10).

\section{Study Population}

We studied 88 consecutive patients admitted to the SICU of the Santa Croce e Carle Teaching Hospital, Cuneo, Italy, for COVID-19, from March 8 to May 1, 2020. The diagnosis was based on acute respiratory failure associated with SARS-CoV-2 RNA detection on nasopharyngeal swab or tracheal aspirate and/or typical COVID-19 features on a pulmonary computed tomography (CT) scan. ${ }^{6}$ Exclusion criteria were age younger than 18 years and patient denial of permission to use their data for research purposes (the great majority of patients could actively give consent; for patients who were too sick to do so, family members were asked whether they were aware of any reason why the patient would deny consent).

\section{Clinical Data}

The past medical history and recent symptoms description were obtained by manually reviewing medical records. Epidemiological exposure was defined as contact with SARS-CoV-2-positive people or staying in an epidemic outbreak area. Initial vital parameters, venous blood tests, arterial blood gas analysis, chest $\mathrm{x}$-ray, as well as the result of the nasopharyngeal swab were gathered from the emergency department (ED) examination. (Additional swabs could be requested when the first one was negative but clinical suspicion for COVID-19 was high.) Upon admission to the SICU, a standardized panel of blood tests was performed, which was repeated the next day and then every 48 hours. Arterial blood gas analysis was performed when clinically indicated, at least twice a day, or following a scheduled time in patients undergoing pronation. Charlson Comorbidity Index ${ }^{7}$ and MuLBSTA score $^{8}$ were calculated based on the collected data.

\section{Imaging}

Chest ultrasonography was performed in the ED at the time of hospitalization and once a day in the SICU. Pulmonary high-resolution computed tomography (HRCT) was performed when clinically indicated or when the results of nasopharyngeal swabs and/or x-ray results were discordant with COVID-19 clinical suspicion. Contrast CT was performed when pulmonary embolism was suspected.

\section{Medical Therapy}

Hydroxychloroquine, antiviral agents, tocilizumab, and ruxolitinib were used in the early phase of the pandemic, then were dismissed after evidence of no efficacy. ${ }^{9-11}$ Steroids and low-molecular-weight heparin were used afterward. Enoxaparin was used at the standard prophylactic dosage, and $70 \%$ of the anticoagulant dosage was also adopted in patients with moderate-to-severe COVID-19 and D-dimer values $>3$ times the normal value. ${ }^{12-14}$ Antibiotics were given when a bacterial superinfection was suspected.

\section{Oxygen and Ventilatory Therapy}

Oxygen support or noninvasive ventilation were started based on patients' respiratory efficacy, estimated by respiratory rate and the ratio of partial pressure of arterial oxygen and fraction of inspired oxygen (P/F ratio). ${ }^{15,16}$ Oxygen support was delivered through nasal cannula, Venturi mask, or reservoir mask. Noninvasive ventilation was performed by continuous positive airway pressure (CPAP) when the P/F ratio was $<250$ or the respiratory rate was $>25$ breaths per minute, using the helmet interface. ${ }^{5,17}$ Prone positioning during CPAP ${ }^{18-20}$ was adopted in patients meeting the acute respiratory distress syndrome (ARDS) criteria ${ }^{21}$ and having persistence of respiratory distress and $\mathrm{P} / \mathrm{F}<300$ after a 1-hour trial of CPAP.

The prone position was maintained based on patient tolerance. P/F ratio was measured before pronation (TO), after 1 hour of prone position (T1), before resupination (T2), and 6 hours after resupination (T3). With the same timing, the patient was asked to rate their comfort in each position, from 0 (lack of comfort) to 10 (optimal comfort). 
Delta $P / F$ was defined as the difference between $P / F$ at T3 and basal P/F at TO.

\section{Outcomes}

Positive outcomes were defined as patient discharge from the SICU or transfer to a lower-intensity care ward for treatment continuation. Negative outcomes were defined as need for transfer to the ICU, transfer to another ward for palliation, or death in the SICU.

\section{Statistical Analysis}

Continuous data are reported as median and interquartile range (IQR); normal distribution of variables was tested using the Shapiro-Wilk test. Categorical variables were reported as absolute number and percentage. The MannWhitney test was used to compare continuous variables between groups, and chi-square test with continuity correction was used for categorical variables. The variables that were most significantly associated with a negative outcome on the univariate analysis were included in a stepwise logistic regression analysis, in order to identify independent predictors of patient outcome. Statistical analysis was performed using JASP (JASP Team) software.

\section{Results}

\section{Study Population}

Of the 88 patients included in the study, $70 \%$ were male; the median age was 66 years (IQR, 60-77). In most patients, the diagnosis of COVID-19 was derived from a positive SARS-CoV-2 nasopharyngeal swab. Six patients, however, maintained a negative swab at all determinations but had clinical and imaging features strongly suggesting COVID-19. No patients met the exclusion criteria. Most patients came from the ED $(n=58$ [66\%]) or general wards $(n=22[25 \%])$, while few were transferred from the ICU ( $n=8$ [9\%]). The median length of stay in the SICU was 4 days (IQR, 2-7). An epidemiological link to affected persons or a known virus exposure was identifiable in 37 patients (42\%).

\section{Clinical, Laboratory, and Imaging Data}

The clinical and anthropometric characteristics of patients are shown in Table 1. Hypertension and smoking habits were prevalent in our population, and the median Charlson
Table 1. Clinical and Anthropometric Characteristics of the Study Population

\begin{tabular}{|c|c|}
\hline Characteristics & Patients $(n=88)$ \\
\hline Age, median (IQR), y & $66(60-77)$ \\
\hline Men & $62(70)$ \\
\hline \multicolumn{2}{|l|}{ Origin } \\
\hline Emergency department & $58(66)$ \\
\hline Lower-intensity wards & $22(25)$ \\
\hline Intensive care unit & $8(9)$ \\
\hline Epidemiological exposure & $37(42)$ \\
\hline \multicolumn{2}{|l|}{ Past medical history } \\
\hline Previous/current smoker & $32(36)$ \\
\hline Hypertension & $43(49)$ \\
\hline Obesity & $22(25)$ \\
\hline Coronary artery disease & $11(12)$ \\
\hline Stroke/transient ischemic attack & $4(5)$ \\
\hline Chronic obstructive pulmonary disease & $5(6)$ \\
\hline Asthma & $4(5)$ \\
\hline Chronic pulmonary disease & $3(3)$ \\
\hline Long-term oxygen therapy & $4(5)$ \\
\hline Diabetes mellitus & $12(14)$ \\
\hline Neoplasia & $14(16)$ \\
\hline Immunodepression & $7(8)$ \\
\hline Pregnancy & $2(2)$ \\
\hline Charlson Comorbidity Index, median (IQR) & $3.0(2.0-5.0)$ \\
\hline ACE-i/ARB & $21(24)$ \\
\hline Direct-acting oral anticoagulants & $3(3)$ \\
\hline Vitamin $\mathrm{K}$ inhibitors & $7(8)$ \\
\hline \multicolumn{2}{|l|}{ Symptoms } \\
\hline Duration before SICU, median (IQR), d & $7.5(5.0-11.0)$ \\
\hline Fever & $69(78)$ \\
\hline Dyspnea & $53(60)$ \\
\hline Cough & $35(40)$ \\
\hline Diarrhea & $16(18)$ \\
\hline Nausea/Vomiting & $5(6)$ \\
\hline Syncope & $3(3)$ \\
\hline Anosmia/ageusia & $1(1)$ \\
\hline \multicolumn{2}{|l|}{ Physical examination at admission } \\
\hline Body mass index & $15(5-15)$ \\
\hline Glasgow Coma Scale & $130(120-148)$ \\
\hline Systolic blood pressure, $\mathrm{mm} \mathrm{Hg}$ & $80(70-85)$ \\
\hline Diastolic blood pressure, $\mathrm{mm} \mathrm{Hg}$ & $85(79-95)$ \\
\hline Heart rate, beats/min & $92(90-95)$ \\
\hline Oxygen saturation, \% & $0.21(0.21-0.28)$ \\
\hline Fraction of inspired oxygen & $37.4(36.5-38.0)$ \\
\hline Temperature, ${ }^{\circ} \mathrm{C}$ & $20(16-28)$ \\
\hline Respiratory rate, breaths/min & \\
\hline
\end{tabular}

Results are expressed as No. (\%) except where indicated.

ACE-i, angiotensin-converting enzyme inhibitor; ARB, angiotensin-receptor blocker; IQR, interquartile range; SICU, subintensive care unit. 
Table 2. Laboratory Results

\begin{tabular}{|c|c|c|c|}
\hline & Time 0 & After 24 hours & After 72 hours \\
\hline $\mathrm{ABG} \mathrm{PaO}_{2}, \mathrm{~mm} \mathrm{Hg}$ & $61(52-70)$ & & \\
\hline $\mathrm{ABG} \mathrm{FIO}_{2}$ & $0.21(0.21-0.30)$ & & \\
\hline ABG P/F ratio & $253(218-291)$ & & \\
\hline WBC, cells/ML (normal range, 4000-10000) & $6500(4900-9900)$ & $7200(4900-9000)$ & $6800(4800-8700)$ \\
\hline 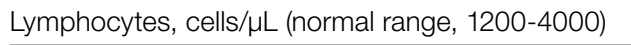 & $800(600-1100)$ & $800(500-1100)$ & $800(600-1100)$ \\
\hline Platelets, cells/ $\mu \mathrm{L}$ (normal range, 150000-450000) & $194,000(149000-278000)$ & $\begin{array}{l}195000 \\
(156000-281000)\end{array}$ & $\begin{array}{l}236000 \\
(189000-315000)\end{array}$ \\
\hline CRP, mg/L (normal range, $\leq 5$ ) & $93(39-154)$ & $116(53-157)$ & $80(44-138)$ \\
\hline Procalcitonin, ng/mL (normal range, $\leq 0-10$ ) & $0.17(0.08-0.40)$ & $0.19(0.10-0.47)$ & $0.16(0.08-0.39)$ \\
\hline Troponin I, pg/L (normal range, <57.3) & $19.9(6.2-39.0)$ & & $18.3(4.9-42.6)$ \\
\hline LDH, U/L (normal range, 120-250) & $364(286-480)$ & & $348(265-406)$ \\
\hline INR (normal range, $\leq 1-10$ ) & $1.18(1.09-1.30)$ & & $1.19(1.14-1.30)$ \\
\hline D-dimer, $\mu \mathrm{g} / \mathrm{mL}$ (normal range, <0.5) & $1.10(0.70-2.10)$ & $1.20(0.80-2.10)$ & $1.20(0.70-2.00)$ \\
\hline NT-proBNP, pg/mL (normal range, $\leq 125$ ) & $391(91-1715)$ & & $747(165-2284)$ \\
\hline Positive nasopharyngeal swabs, No. (\%) & $72(82)$ & & $10(63)$ \\
\hline
\end{tabular}

Results are expressed as median (interquartile range) except where noted.

$\mathrm{ABG}$, arterial blood gas analysis; CRP, C-reactive protein; $\mathrm{FIO}_{2}$; fraction of inspired oxygen; INR, international normalized ratio; LDH, lactate dehydrogenase; NT-proBNP, N-terminal pro-brain natriuretic peptide; P/F ratio, ratio of partial pressure of arterial oxygen and fraction of inspired oxygen; PaO ${ }_{2}$, partial pressure of arterial oxygen; WBC, white blood cell count.

Comorbidity Index was 3. Most patients experienced fever, dyspnea, and cough during the days before hospitalization.

Laboratory data showed a marked inflammatory milieu in all studied patients, both at baseline and after 24 and 72 hours. Lymphopenia was observed, along with a significant increase of lactate dehydrogenase $(\mathrm{LDH})$, C-reactive protein (CPR), and D-dimer, and a mild increase of procalcitonin. $\mathrm{N}$-terminal pro-brain natriuretic peptide (NT-proBNP) values were also increased, with normal troponin I values (Table 2).

Chest $\mathrm{x}$-rays were obtained in almost all patients, while HRCT was performed in nearly half of patients. Complete bedside pulmonary ultrasonography data were available for 64 patients. Heterogeneous pulmonary alterations were found, regardless of the radiological technique, and multilobe infiltrates were the prevalent radiological pattern (73\%) (Table 3). Seven patients (8\%) were diagnosed with associated pulmonary embolism.

\section{Medical Therapy}

Most patients (89\%) received hydroxychloroquine, whereas steroids were used in one-third of the population (36\%).
Immunomodulators (tocilizumab and ruxolitinib) were restricted to 12 patients (14\%). Empirical antiviral therapy was introduced in the first 41 patients (47\%). Enoxaparin was the default agent for thromboembolism prophylaxis, and 6 patients (7\%) received $70 \%$ of the anticoagulating dose.

\section{Oxygen and Ventilatory Therapy}

Basal median P/F ratio was 253 (IQR, 218-291), and respiratory rate at triage was 20 breaths/min (IQR, 16-28), underlining a moderate-to-severe respiratory insufficiency at presentation. A total of 69 patients (78\%) underwent CPAP, with a median positive end-expiratory pressure (PEEP) of $10.0 \mathrm{~cm} \mathrm{H}_{2} \mathrm{O}(\mathrm{IQR}, 7.5-10.0)$ and fraction of inspired oxygen $\left(\mathrm{FIO}_{2}\right)$ of 0.40 (IQR, 0.40-0.50). In 37 patients (42\%) who received ongoing CPAP, prone positioning was adopted. In this subgroup, respiratory rate was not significantly different from baseline to resupination (24 vs 25 breaths/min). The median P/F improved from 197 (IQR, 154-236) at baseline to 217 (IQR, 180-262) after pronation (the duration of the prone position was variable, depending on patients' tolerance: 1 to 6 hours or every pronation cycle). The median delta P/F ratio was 39.4 (IQR, -17.0 to 78.0$)$. 


\begin{tabular}{|c|c|c|c|c|c|c|}
\hline & $\begin{array}{l}\text { No. of } \\
\text { patients }\end{array}$ & $\begin{array}{l}\text { Normal } \\
\text { pattern }\end{array}$ & $\begin{array}{l}\text { Interstitial } \\
\text { abnormalities }\end{array}$ & $\begin{array}{l}\text { Unilateral } \\
\text { consolidations }\end{array}$ & $\begin{array}{l}\text { Bilateral } \\
\text { consolidations }\end{array}$ & $\begin{array}{l}\text { Interstitial } \\
\text { abnormalities and } \\
\text { consolidations }\end{array}$ \\
\hline Chest x-ray & 75 & $11(15)$ & $8(11)$ & $11(15)$ & $38(51)$ & $7(9)$ \\
\hline \multirow[t]{2}{*}{ CT scan } & 39 & $3(8)$ & $1(3)$ & $3(8)$ & $24(62)$ & $8(21)$ \\
\hline & & $\begin{array}{l}\text { Normal } \\
\text { pattern }\end{array}$ & Focal B lines & $\begin{array}{l}\text { Confluent B lines } \\
\text { (wet lung) }\end{array}$ & $\begin{array}{l}\text { Consolidations and } \\
\text { confluent B lines } \\
\text { (dry lung) }\end{array}$ & \\
\hline $\begin{array}{l}\text { Lung ultrasound } \\
\text { at baseline (ED) }\end{array}$ & 64 & $3(5)$ & $22(34)$ & $7(11)$ & $32(50)$ & \\
\hline Multi-lobe disease & 88 & $64(73)$ & & & & \\
\hline
\end{tabular}

\section{Outcomes}

A total of 28 patients (32\%) had a negative outcome in the SICU: 8 patients (9\%) died, having no clinical indication for higher-intensity care; 6 patients (7\%) were transferred to general wards for palliation; and 14 patients (16\%) needed an upgrade of cure intensity and were transferred to the ICU. Of these 14 patients, 9 died in the ICU. The total in-hospital mortality of COVID-19 patients, including patients transferred from the SICU to general wards in fair condition, was $27 \%(n=24)$. Clinical, laboratory, and therapeutic characteristics between the 2 groups are shown in Table 4.

Patients who had a negative outcome were significantly older and had more comorbidities, as suggested by a significantly higher prevalence of diabetes and higher Charlson Comorbidity scores (reflecting the mortality risk based on age and comorbidities). The median MuLBSTA score, which estimates the 90-day mortality risk from viral pneumonia, was also higher in patients who had a negative outcome (9.33\%). Symptom occurrence was not different in patients with a negative outcome (apart from cough, which was less frequent), but these patients underwent hospitalization earlier-since the appearance of their first COVID-19 symptoms-compared to patients who had a positive outcome. No difference was found in antihypertensive therapy with angiotensin-converting enzyme inhibitors or angiotensin-receptor blockers among outcome groups.

More pronounced laboratory abnormalities were found in patients who had a negative outcome, compared to patients who had a positive outcome: lower lympho- cytes and higher C-reactive protein (CRP), procalcitonin, D-dimer, LDH, and NT-proBNP. We found no differences in the radiological distribution of pulmonary involvement in patients who had negative or positive outcomes, nor in the adopted medical treatment.

Data showed no difference in CPAP implementation in the 2 groups. However, prone positioning had been more frequently adopted in the group of patients who had a positive outcome, compared with patients who had a negative outcome. No differences of basal P/F were found in patients who had a negative or positive outcome, but the median P/F after 6 hours of prone position was significantly lower in patients who had a negative outcome. The delta P/F ratio did not differ in the 2 groups of patients.

\section{Multivariate Analysis}

A logistic regression model was created, including the variables significantly associated with outcomes in the univariate analysis (age, sex, history of diabetes, lymphocytes, CRP, procalcitonin, LDH, NT-proBNP, and D-dimer). In the multivariate analysis, independent predictors of a negative outcome were history of diabetes (odds ratio [OR], 8.22; 95\% Cl, 1.50-44.70; $P=.015$ ), high $\mathrm{D}$-dimer values (OR, 1.28; Cl, 1.04-1.57; $P=.019$ ), high LDH values (OR, 1.003; $\mathrm{Cl}, 1.000-1.006 ; P=.039)$, and low lymphocytes count (OR, 0.996; Cl, 0.993-0.999; $P=.004$ ).

\section{Discussion}

\section{Role of Subintensive Units and Mortality}

The novelty of our report is its attempt to investigate the 
Table 4. Variables Comparison by Outcome

\begin{tabular}{|c|c|c|c|}
\hline & $\begin{array}{l}\text { Positive outcome } \\
\mathrm{N}=60(68 \%)\end{array}$ & $\begin{array}{l}\text { Negative outcome } \\
\mathrm{N}=28(32 \%)\end{array}$ & $P$ value \\
\hline Age, y & $64(56-74)$ & $73(63-86)$ & $.005^{\mathrm{a}}$ \\
\hline Men & $42(70)$ & $20(71)$ & 1.000 \\
\hline Body mass index & $26(24-28)$ & $25(23-28)$ & .100 \\
\hline \multicolumn{4}{|l|}{ Past medical history } \\
\hline Previous/current smoker & $18(30)$ & $14(50)$ & .060 \\
\hline Diabetes mellitus & $3(5)$ & $9(32)$ & $.002^{\mathrm{a}}$ \\
\hline Hypertension & $25(42)$ & $18(64)$ & .080 \\
\hline History of CAD & $8(13)$ & $3(11)$ & 1.000 \\
\hline Previous stroke/TIA & $1(2)$ & $3(11)$ & .178 \\
\hline Charlson Comorbidity Index & $3.0(1.7-4.0)$ & $4.0(2.7-5.0)$ & $.008^{a}$ \\
\hline MuLBSTA score & $9(6-11)$ & $13(11-15)$ & $<.001^{\mathrm{a}}$ \\
\hline ACE-i/ARB & $2(3)$ & $9(32)$ & .350 \\
\hline Direct-acting oral anticoagulants & $1(2)$ & $2(7)$ & .491 \\
\hline Vitamin $\mathrm{K}$ inhibitors & $4(7)$ & $4(14)$ & .818 \\
\hline \multicolumn{4}{|l|}{ Symptoms and examination } \\
\hline Fever & $48(80)$ & $21(75)$ & .800 \\
\hline Cough & $31(52)$ & $4(14)$ & $.002^{a}$ \\
\hline Dyspnea & $37(62)$ & $16(57)$ & .865 \\
\hline Symptom duration before SICU, d & $9.5(6.7-12.0)$ & $7.0(5.0-10.0)$ & $.015^{a}$ \\
\hline Basal oxygen saturation, \% & $93(90-96)$ & $92(88-93)$ & .100 \\
\hline Respiratory rate, breaths/min & $22(17-28)$ & $19(15-25)$ & .110 \\
\hline \multicolumn{4}{|l|}{ Laboratory results } \\
\hline $\mathrm{P} / \mathrm{F}$ ratio, time 0 & $269(243-311)$ & $236(185-250)$ & .340 \\
\hline WBC time 0 , cells $/ \mu \mathrm{L}$ & $6100(4900-9400)$ & $9000(4600-11700)$ & .180 \\
\hline Lymphocytes time 0 , cells/ $\mu \mathrm{L}$ & $900(700-1300)$ & $600(400-800)$ & $<.001^{a}$ \\
\hline CRP time $0, \mathrm{mg} / \mathrm{L}$ & $77(36-137)$ & $154(92-211)$ & $.002^{\mathrm{a}}$ \\
\hline Procalcitonin time $0, \mathrm{ng} / \mathrm{mL}$ & $0.12(0.08-0.22)$ & $0.34(0.20-1.05)$ & $<.001^{a}$ \\
\hline Troponin I time 0, pg/L & $16.7(4.2-29.7)$ & $26.8(12.2-62.3)$ & $.029^{a}$ \\
\hline $\mathrm{LDH}$ time $0, \mathrm{U} / \mathrm{L}$ & $333(274-422)$ & $453(331-565)$ & $.005^{a}$ \\
\hline D-dimer time $0, \mu \mathrm{g} / \mathrm{mL}$ & $0.86(0.59-1.67)$ & $1.92(1.35-5.51)$ & $<.001^{a}$ \\
\hline NT-proBNP time $0, \mathrm{pg} / \mathrm{mL}$ & $245(65-1062)$ & $1335(597-4490)$ & $.006^{a}$ \\
\hline Positive swab & $56(93)$ & $26(93)$ & .959 \\
\hline \multicolumn{4}{|l|}{ Therapy } \\
\hline Antiviral drugs & $29(48)$ & $12(43)$ & .941 \\
\hline Hydroxychloroquine & $57(95)$ & $21(75)$ & .283 \\
\hline Tocilizumab & $7(12)$ & $3(11)$ & 1.000 \\
\hline Antibiotics & $32(53)$ & $20(71)$ & $.010^{\mathrm{a}}$ \\
\hline Steroids & $21(35)$ & $10(36)$ & .308 \\
\hline Enoxaparin (70\% or full anticoagulant dose) & $18(30)$ & $8(29)$ & .518 \\
\hline \multicolumn{4}{|l|}{ Pronation variables } \\
\hline Pronation & $30(50)$ & $7(25)$ & $.048^{a}$ \\
\hline No. of hours in prone position & $4.75(4.00-6.75)$ & $4.00(3.00-6.50)$ & .569 \\
\hline $\mathrm{P} / \mathrm{F}$ ratio before pronation & $203(164-249)$ & $171(146-202)$ & .124 \\
\hline P/F ratio after 6 hours of pronation & 249 (195-268) & $144(140-168)$ & $.006^{\mathrm{a}}$ \\
\hline Delta P/F after pronation & $39.5(-1.5$ to 83.0$)$ & $-20.0(-48.0$ to 47.0$)$ & .192 \\
\hline
\end{tabular}

Results are expressed as median (interquartile range) and No. (\%).

${ }^{a} P<.05$, statistically significant difference.

ACE-i, angiotensin-converting enzyme inhibitor; ARB, angiotensin-receptor blocker; BMI, body mass index; CAD, coronary artery disease; CRP, C-reactive protein; LDH, lactate dehydrogenase; NT-proBNP, N-terminal pro-brain natriuretic peptide; P/F ratio, ratio of partial pressure of arterial oxygen and fraction of inspired oxygen; SICU, sub-intensive care unit; TIA, transient ischemic attack; WBC, white blood cell count. 
specific group of COVID-19 patients admitted to a SICU. In Italy, SICUs receive acutely ill, spontaneously breathing patients who need (invasive) hemodynamic monitoring, vasoactive medication, renal replacement therapy, chesttube placement, thrombolysis, and respiratory noninvasive support. The nurse-to-patient ratio is higher than for general wards (usually 1 nurse to every 4 or 5 patients), though lower than for ICUs. In northern Italy, a great number of COVID-19 patients have required this kind of high-intensity care during the pandemic: Noninvasive ventilation support had to be maintained for several days, pronation maneuvers required a high number of people 2 or 3 times a day, and strict monitoring had to be assured. The SICU setting allows patients to buy time as a bridge to progressive reduction of pulmonary involvement, sometimes preventing the need for intubation.

The high prevalence of negative outcomes in the SICU underlines the complexity of COVID-19 patients in this setting. In fact, published data about mortality for patients with severe COVID-19 pneumonia are similar to ours. ${ }^{22,23}$

\section{Clinical, Laboratory, and Imaging Data}

Our analysis confirmed a high rate of comorbidities in COVID-19 patients ${ }^{24}$ and their prognostic role with age. ${ }^{25,26} \mathrm{~A}$ marked inflammatory milieu was a negative prognostic indicator, and associated concomitant bacterial superinfection could have led to a worse prognosis (procalcitonin was associated with negative outcomes). ${ }^{27}$ The cardiovascular system was nevertheless stressed, as suggested by higher values of NT-proBNP in patients with negative outcomes, which could reflect sepsisrelated systemic involvement. ${ }^{28}$

It is known that the pulmonary damage caused by SARS-CoV-2 has a dynamic radiological and clinical course, with early areas of subsegmental consolidation, and bilateral ground-glass opacities predominating later in the course of the disease. ${ }^{29}$ This could explain why in our population we found no specific radiological pattern leading to a worse outcome.

\section{Medical Therapy}

No specific pharmacological therapy was found to be associated with a positive outcome in our study, just like antiviral and immunomodulator therapies failed to demonstrate effectiveness in subsequent pandemic surges. The low statistical power of our study did not allow us to give insight into the effectiveness of steroids and heparin at any dosage.

\section{PEEP Support and Prone Positioning}

Continuous positive airway pressure was initiated in the majority of patients and maintained for several days. This was an absolute novelty, because we rarely had to keep patients in helmets for long. This was feasible thanks to the SICU's high nurse-to-patient ratio and the possibility of providing monitored sedation. Patients who could no longer tolerate CPAP helmets or did not improve with CPAP support were evaluated with anesthetists for programming further management. No initial data on respiratory rate, level of hypoxemia, or oxygen support need (level of PEEP and $\mathrm{FIO}_{2}$ ) could discriminate between outcomes.

Prone positioning during CPAP was implemented in $42 \%$ of our study population: P/F ratio amelioration after prone positioning was highly variable, ranging from very good P/F ratio improvements to few responses or no response. No significantly greater delta P/F ratio was seen after the first prone positioning cycle in patients who had a positive outcome, probably due to the small size of our population, but we observed a clear positive trend. Interestingly, patients showing a negative outcome had a lower percentage of long-term responses to prone positioning: 6 hours after resupination, they lost the benefit of prone positioning in terms of P/F ratio amelioration. Similarly, a greater number of patients tolerating prone positioning had a positive outcome. These data give insight on the possible benefits of prone positioning in a noninvasively supported cohort of patients, which has been mentioned in previous studies. . $^{30,31}$

\section{Outcomes and Variables Associated With Negative Outcomes}

After correction for age and sex, we found in multiple regression analysis that higher D-dimer and LDH values, lymphopenia, and history of diabetes were independently associated with a worse outcome. Although our results had low statistical significance, we consider the trend of the obtained odds ratios important from a clinical point of view. These results could lead to greater attention being placed on COVID-19 patients who 
present with these characteristics upon their arrival to the ED because they have increased risk of death or intensive care need. Clinicians should consider SICU admission for these patients in order to guarantee closer monitoring and possibly more aggressive ventilatory treatments, earlier pronation, or earlier transfer to the ICU.

\section{Limitations}

The major limitation to our study is undoubtedly its statistical power, due to its relatively low patient population. Particularly, the small number of patients who underwent pronation did not allow speculation about the efficacy of this technique, although preliminary data seem promising. However, ours is among the first studies regarding patients with COVID-19 admitted to a SICU, and these preliminary data truthfully describe the Italian, and perhaps international, experience with the first surge of the pandemic.

\section{Conclusions}

Our data highlight the primary role of the SICU in COVID19 in adequately treating critically ill patients who have high care needs different from intubation, and who require noninvasive ventilation for prolonged times as well as frequent pronation cycles. This setting of care may represent a valid, reliable, and effective option for critically ill respiratory patients. History of diabetes, lymphopenia, and high D-dimer and LDH values are independently associated with negative outcomes, and patients presenting with these characteristics should be strictly monitored.

Acknowledgments: The authors thank the Informatica System S.R.L., as well as Allessando Mendolia for the pro bono creation of the ISCovidCollect data collecting app.

Corresponding author: Sara Abram, MD, via Coppino, 12100 Cuneo, Italy; sara.abram84@gmail.com.

Disclosures: None.

doi:10.12788/jcom.0080

\section{References}

1. Plate JDJ, Leenen LPH, Houwert M, Hietbrink F. Utilisation of intermediate care units: a systematic review. Crit Care Res Pract. 2017;2017:8038460. doi:10.1155/2017/8038460

2. Antonelli M, Conti G, Esquinas $\mathrm{A}$, et al. A multiple-center survey on the use in clinical practice of noninvasive ventilation as a first-line intervention for acute respiratory distress syndrome. Crit Care Med. 2007;35(1):18-25. doi:10.1097/01.CCM.0000251821.44259.F3

3. Patel BK, Wolfe KS, Pohlman AS, Hall JB, Kress JP. Effect of noninvasive ventilation delivered by helmet vs face mask on the rate of endotracheal intubation in patients with acute respiratory distress syndrome: a randomized clinical trial. JAMA. 2016;315(22):24352441. doi:10.1001/jama.2016.6338

4. Mas A, Masip J. Noninvasive ventilation in acute respiratory failure. Int J Chron Obstruct Pulmon Dis. 2014;9:837-852. doi:10.2147/ COPD.S42664

5. Bellani G, Patroniti N, Greco M, Foti G, Pesenti A. The use of helmets to deliver non-invasive continuous positive airway pressure in hypoxemic acute respiratory failure. Minerva Anestesiol. 2008;74(11):651-656.

6. Lomoro P, Verde F, Zerboni F, et al. COVID-19 pneumonia manifestations at the admission on chest ultrasound, radiographs, and CT: single-center study and comprehensive radiologic literature review. Eur J Radiol Open. 2020;7:100231. doi:10.1016/j. ejro.2020.100231

7. Charlson ME, Pompei P, Ales KL, MacKenzie CR. A new method of classifying prognostic comorbidity in longitudinal studies: development and validation. J Chronic Dis. 1987;40:373-383. doi:10.1016/0021-9681(87)90171-8

8. Guo L, Wei D, Zhang X, et al. Clinical features predicting mortality risk in patients with viral pneumonia: the MuLBSTA score. Front Microbiol. 2019;10:2752. doi:10.3389/fmicb.2019.02752

9. Lombardy Section Italian Society Infectious and Tropical Disease. Vademecum for the treatment of people with COVID-19. Edition 2.0, 13 March 2020. Infez Med. 2020;28(2):143-152.

10. Wang $M$, Cao $R$, Zhang $L$, et al. Remdesivir and chloroquine effectively inhibit the recently emerged novel coronavirus (2019nCoV) in vitro. Cell Res. 2020;30(3):269-271. doi:10.1038/ s41422-020-0282-0

11. Cao B, Wang $Y$, Wen $D$, et al. A trial of lopinavir-ritonavir in adults hospitalized with severe Covid-19. N Engl J Med. 2020;382(19):1787-1799. doi:10.1056/NEJMoa2001282

12. Stone $\mathrm{JH}$, Frigault MJ, Serling-Boyd NJ, et al; BACC Bay Tocilizumab Trial Investigators. Efficacy of tocilizumab in patients hospitalized with Covid-19. N Engl J Med. 2020;383(24):23332344. doi:10.1056/NEJMoa2028836

13. Shastri MD, Stewart N, Horne J, et al. In-vitro suppression of IL-6 and IL-8 release from human pulmonary epithelial cells by non-anticoagulant fraction of enoxaparin. PLoS One. 2015;10(5):e0126763. doi:10.1371/journal.pone.0126763

14. Milewska A, Zarebski M, Nowak P, Stozek K, Potempa J, Pyrc K. Human coronavirus NL63 utilizes heparin sulfate proteoglycans for attachment to target cells. J Virol. 2014;88(22):13221-13230. doi:10.1128/JVI.02078-14

15. Marietta M, Vandelli P, Mighali P, Vicini R, Coluccio V, D'Amico R; COVID-19 HD Study Group. Randomised controlled trial comparing efficacy and safety of high versus low low-molecular weight heparin dosages in hospitalized patients with severe COVID-19 pneumonia and coagulopathy not requiring invasive mechanical ventilation (COVID-19 HD): a structured summary of a study protocol. Trials. 2020;21(1):574. doi:10.1186/s13063-020-04475-z

16. Marshall JC, Cook DJ, Christou NV, Bernard GR, Sprung CL, Sibbald WJ. Multiple organ dysfunction score: a reliable descriptor of a complex clinical outcome. Crit Care Med. 1995;23(10):16381652. doi:10.1097/00003246-199510000-00007

17. Sinha P, Calfee CS. Phenotypes in acute respiratory distress syndrome: moving towards precision medicine. Curr Opin Crit Care. 
2019;25(1):12-20. doi:10.1097/MCC.0000000000000571

18. Lucchini A, Giani M, Isgrò S, Rona R, Foti G. The "helmet bundle" in COVID-19 patients undergoing non-invasive ventilation. Intensive Crit Care Nurs. 2020;58:102859. doi:10.1016/j.iccn.2020.102859

19. Ding L, Wang L, Ma W, He H. Efficacy and safety of early prone positioning combined with HFNC or NIV in moderate to severe ARDS: a multi-center prospective cohort study. Crit Care. 2020;24(1):28. doi:10.1186/s13054-020-2738-5

20. Scaravilli V, Grasselli G, Castagna L, et al. Prone positioning improves oxygenation in spontaneously breathing nonintubated patients with hypoxemic acute respiratory failure: a retrospective study. J Crit Care. 2015;30(6):1390-1394. doi:10.1016/j.jcrc.2015.07.008

21. Caputo ND, Strayer RJ, Levitan R. Early self-proning in awake, non-intubated patients in the emergency department: a single ED's experience during the COVID-19 pandemic. Acad Emerg Med. 2020;27(5):375-378. doi:10.1111/acem.13994

22. ARDS Definition Task Force; Ranieri VM, Rubenfeld GD, Thompson $\mathrm{BT}$, et al. Acute respiratory distress syndrome: the Berlin Definition. JAMA. 2012;307(23):2526-2533. doi:10.1001/jama.2012.5669

23. Petrilli CM, Jones SA, Yang J, et al. Factors associated with hospital admission and critical illness among 5279 people with coronavirus disease 2019 in New York City: prospective cohort study. BMJ. 2020;369:m1966. doi:10.1136/bmj.m1966

24. Docherty AB, Harrison EM, Green CA, et al; ISARIC4C investigators. Features of 20133 UK patients in hospital with Covid-19 using the ISARIC WHO Clinical Characterisation Protocol: prospective observational cohort study. BMJ. 2020;369:m1985. doi:10.1136/bmj.m1985
25. Richardson S, Hirsch JS, Narasimhan M, et al. Presenting characteristics, comorbidities, and outcomes among 5700 patients hospitalized with COVID-19 in the New York City area. JAMA. 2020;323(20):2052-2059. doi:10.1001/jama.2020.6775

26. Muniyappa R, Gubbi S. COVID-19 pandemic, coronaviruses, and diabetes mellitus. Am J Physiol Endocrinol Metab. 2020;318(5):E736-E741. doi:10.1152/ajpendo.00124.2020

27. Guo W, Li M, Dong Y, et al. Diabetes is a risk factor for the progression and prognosis of COVID-19. Diabetes Metab Res Rev. 2020:e3319. doi:10.1002/dmrr.3319

28. Chen N, Zhou M, Dong X, et al. Epidemiological and clinical characteristics of 99 cases of 2019 novel coronavirus pneumonia in Wuhan, China: a descriptive study. Lancet. 2020;395(10223):507513. doi:10.1016/S0140-6736(20)30211-7

29. Kooraki S, Hosseiny M, Myers L, Gholamrezanezhad A. Coronavirus (COVID-19) outbreak: what the Department of Radiology should know. J Am Coll Radiol. 2020;17(4):447-451. doi:10.1016/j. jacr.2020.02.008

30. Coppo A, Bellani G, Winterton D, et al. Feasibility and physiological effects of prone positioning in non-intubated patients with acute respiratory failure due to COVID-19 (PRON-COVID): a prospective cohort study. Lancet Respir Med. 2020;8(8):765-774. doi:10.1016/ S2213-2600(20)30268-X

31. Weatherald J, Solverson K, Zuege DJ, Loroff N, Fiest KM, Parhar KKS. Awake prone positioning for COVID-19 hypoxemic respiratory failure: a rapid review. J Crit Care. 2021;61:63-70. doi:10.1016/j. jcrc.2020.08.018

\section{CALL for REVIEWERS}

The Journal of Clinical Outcomes Management welcomes applications

from physicians, directors of pharmacy, nurse leaders,

and others working in inpatient and ambulatory settings

to serve as peer reviewers.

You will not be asked to review more than 3 times per year.

The following medical specialties are especially of interest: cardiology,

critical care, endocrinology, hematology/oncology, hospital medicine,

infectious diseases, mental health, neurology, nephrology,

pulmonary disease, and rheumatology.

To apply to be a peer reviewer, email your CV along with a description of your subject areas of interest to

rlitchkofski@mdedge.com.

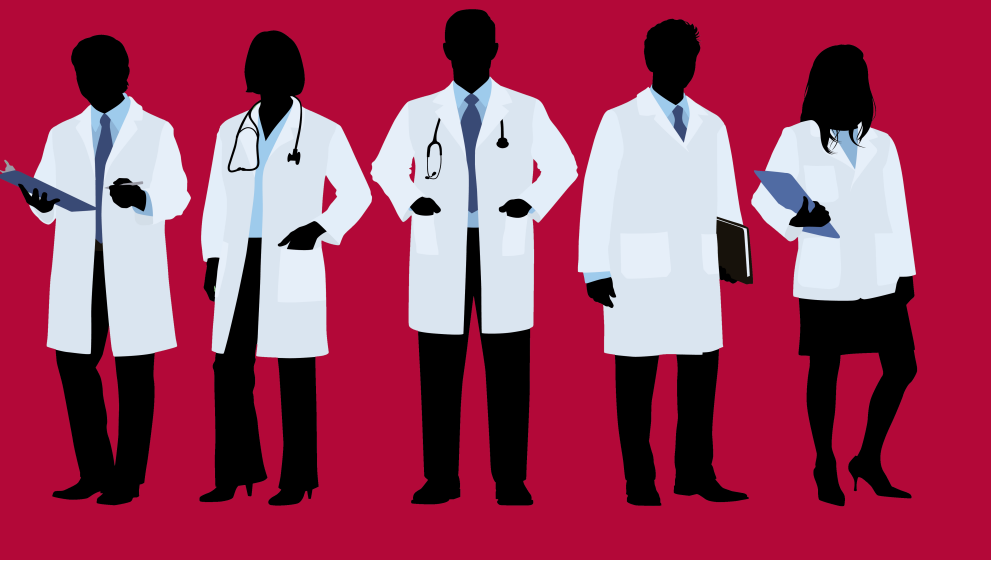

